\title{
A Comparative Study of Ear Diseases in School Children from Lower versus Higher Socioeconomic Status
}

\author{
Yohanna Mairiga Takwoingi' ${ }^{1}$, Mohammed Bello Fufore ${ }^{2 *}\left(\mathbb{D}\right.$, Abubakar Umar ${ }^{2}$, \\ Gabsari Emmanuel Musa2 ${ }^{2}$ Wuni Ari Thimnu'2, Isah Abdullahi ${ }^{3}$
}

${ }^{1}$ Department of ENT, City Hospital, Birmingham, UK

${ }^{2}$ Department of ENT, Federal Medical Centre, Yola, Nigeria

${ }^{3}$ Department of ENT, University of Maiduguri Teaching Hospital, Maiduguri, Nigeria

Email: *drbellofufore@yahoo.com

How to cite this paper: Takwoingi, Y.M., Fufore, M.B., Umar, A., Musa, G.E., Thimnu, W.A. and Abdullahi, I. (2021) A Comparative Study of Ear Diseases in School Children from Lower versus Higher Socioeconomic Status. International Journal of Otolaryngology and Head \& Neck Surgery, 10, 107-118.

https://doi.org/10.4236/ijohns.2021.102012

Received: February 24, 2021

Accepted: March 28, 2021

Published: March 31, 2021

Copyright $\odot 2021$ by author(s) and Scientific Research Publishing Inc. This work is licensed under the Creative Commons Attribution International License (CC BY 4.0).

http://creativecommons.org/licenses/by/4.0/

\begin{abstract}
Background: Preventable otologic conditions have been found to be important health issues among paediatric age group. Poor socioeconomic status and inappropriate management services in developing countries lead to various complications despite the fact that most of these diseases are self-limiting. The aim of this study was to determine the prevalence and pattern of ear diseases in school children of high and low socioeconomic status in Yola, Nigeria. Methods: This study was conducted in March 2017 in two primary schools (private and public) in Yola among 6 - 8 years old pupils. Approval for the study was obtained from Federal Medical Centre, Yola and consent was obtained from the parents/guardians and the school authorities. Using a health questionnaire, a brief ENT history was obtained from children in years 1 and 2 of each school. Otoscopic examination, audiometry and tympanometry were then carried out. Data collected was analysed using SPSS version 20. Results: One hundred and three children were studied. The age range was 6 8 with mean age of $6.8 \pm 0.9$ and 53 (51.5\%) boys. Fifty-two (50.5\%) were from public school (low socio-economic class) and 51 (49.5\%) from private (high social class). Wax was the most common ear condition encountered affecting 37 (35.9\%) children, and the number was similar in both groups. Otitis media with effusion (OME) was encountered in seven children evenly split between the two groups showing a point incidence of $6.8 \%$. There was hearing loss in $13(12.6 \%)$ children, and this was also similar in the two groups. Conclusion: Wax impaction was the commonest otologic disease encountered. Our study also showed a point incidence of $6.8 \%$ for OME, but there was no statistical difference between the two groups, and neither was there
\end{abstract}


any statistically significant difference between the two groups in any of the

other diseases encountered.

\section{Keywords}

Children, Glue-Ear, Hearing Loss, Social Status, Wax

\section{Background}

Prevalence of otologic conditions is high among school going children which accounts for about one-third of patients attending the otorhinolaryngology clinics whereas almost one-fifth of cases attending paediatric out-patient clinics suffer from otorhinolaryngological related diseases [1] [2] [3]. Preventable otologic conditions have been found to be important health issues among paediatric age group [1] [2]. Poor socioeconomic status and inappropriate management services in developing countries lead to various complications despite the fact that most of these diseases are self-limiting [1].

Normal hearing plays a vital role in good psycho-social development of children [4]. Otologic diseases causing hearing impairment during early childhood might have negative effect on the child, which may cause delayed cognitive skills, speech and language development often resulting in poor performance in school compared to those with normal hearing threshold [3] [4] [5] [6]. However, despite the high prevalence rates of otologic diseases among paediatric age group and its possible consequences on psycho-social development of these children, there are very few studies carried out that compared ear diseases of children from high versus low socioeconomic classes; and most, if not all, of the studies were from Asia, and none of these available studies appear to have been carried out from the Northern part of the country [7]-[12]. It therefore becomes imperative to estimate the magnitude and distribution of ear diseases that lead to hearing impairment in school-going children to enable them a better future and also for proper planning and implementation of health care measures. The aim of this study was to determine the prevalence and pattern of ear diseases in school children of high and low socioeconomic status in Yola, Nigeria.

\section{Patients and Methods}

This study was conducted in March 2017 in two primary schools in Yola (a private and a public school). The private primary school, an expensive school where children of the elites attend (i.e. children of those in social class I) and a public primary school where children of the less privileged attend (i.e. children of those in social class V) [13]. Based on the current national minimum wage, the least annual salary of a junior civil servant is around 216,000 naira per annum [14], and the annual school fees per child in this current private school is closed to six hundred thousand naira (i.e. about three times the annual salary of a junior civil servant) whereas those in the public school pay less than 5000 naira as school 
fees per annum. Therefore, only parents from high socio-economic class (i.e. those in social class I) can afford to enrol their children in this particular private school. Basic (primary) one and two pupils (age ranging between 6 and 8 years) from the two schools were recruited for the study after obtaining approval from Federal Medical Centre, Yola and consent from the parents/guardians and the school authorities and assent from the children.

The sample size was calculated using Fisher's formula for cross-sectional studies: $n=Z^{2} p q / d^{2}$ where $\mathrm{p}=$ prevalence (6.5\%) [15], $q=p-1, Z=$ standard normal deviate (which is 1.96 at $95 \%$ confidence interval) and $\mathrm{d}=$ degree of precision at $95 \%$ confidence interval. Thus: $n=3.842 \times 0.065 \times 0.935 / 0.05 \times 0.05 \approx$ 94. However, to make up for attrition $(10.0 \%$ attrition, $94 / 100 \times 10=9.4$ which was approximately 9 was added). Therefore, 103 pupils were recruited.

Multi-staged sampling technique was used to enrol the pupils from the two schools. The two schools (public and private) were randomly selected. Those enrolled were pupils in years one and two (Primary 1 and 2). There were 100 eligible pupils in the private school (25 each in primary $1 \mathrm{~A}, 1 \mathrm{~B}, 2 \mathrm{~A}$ and $2 \mathrm{~B}$ ) and there were 293 eligible pupils in the public school (50 each in primary 1A, 1B, 2A and $2 \mathrm{~B}$; and 46 in primary $1 \mathrm{C}$ and 47 in primary $2 \mathrm{C}$ ). The selection was done in stages.

Selection of number of pupils per school was carried out in stage 1 and almost equal number was assigned to each school (51 from private and 52 from the public school). In stage 2, year one and two were selected from each school. For the private school, 51 divided by 2 ( 25 and 26 were selected from year one and two respectively) while for the public school, 52 divided by 2 (26 each were enrolled from primary one and two). Stage 3 (selection of class); For the 25 in the private school selected in year one, they were again divided into two and 13 were assigned to primary $1 \mathrm{~A}$ and 12 to primary $1 \mathrm{~B}$ and the same process was done for year two. For the 26 in the public school selected in year one, they were divided into three and 9 each were assigned to year $1 \mathrm{~A}$ and $1 \mathrm{~B}$, and 8 to year $1 \mathrm{C}$. The same was done for year two. Stage 4 (selection of participants); for every class where the number of those agreed to take part exceeds the number allocated to the class, then the participants were chosen by balloting and only those who picked "Yes" were enrolled.

Data was collated using a structured pretested questionnaire consisting of five (5) basic sections: demography, brief history, examination, pure tone audiometry and tympanometry. A brief ENT history was obtained and Headlight was used to examine the pinna and external auditory canal and Welch Allyn (Microview) rechargeable otoscope was used to examine the external auditory canal and tympanic membrane for wax, foreign body, discharge, and tympanic membrane for retraction, fullness or perforation. The diagnosis of ear wax was made when the wax obscured the view of the tympanic membrane (irrespective of whether it is impacted or not). Those with impacted wax had it removed by either manual (using Cawthorne wax hook and/or Jobson-Horne probe) or by syringing and had audiometric assessment three days after cleaning the ear. 
The pure tone audiometry was done using a Diagnostic Audiometer (Model AD-226, USA), calibrated to ISO standard. The test was carried out in the quietest room within the schools' premises where the mean ambient noise level of the test room was $37.6 \mathrm{~dB}$ (less than $40 \mathrm{~dB}$ ) [16] using a Smartphone sound pressure level meter, (Sound Meter-Decibel meter and Noise meter, Tools Dev, 4.6, version 2.1.6).

The pupils that were tested were seated on a chair in the test room and the procedure was clearly explained to each pupil before commencement. The pupils wore the headphones and signified on hearing the tone by pressing on a small hand-held button as soon as the tone was heard. Pure tones were delivered to each ear consecutively through the ear phones to test for air conduction (AC). Both ears were tested for hearing impairment. The test was first conducted for the right ear at 1000 , then $2000,4000,8000$ hertz, then $500 \mathrm{~Hz}$ and $250 \mathrm{~Hz}$ in that order [17] [18]. The test started at $40 \mathrm{~dB}$ HL, if audible then was reduced in $10 \mathrm{~dB}$ steps till no response occurred, then it was increased in $5 \mathrm{~dB}$ steps till a response occurred and the results were plotted [17] [18]. The left ear was then tested and the same process for air conduction was repeated. For bone conduction (BC) test, the bone vibrator was placed on the mastoid bone of the test ear delivering different tones at frequencies of 500, 1000, 2000, 4000 hertz [17] [18].

The results of the audiometric tests for each ear were recorded separately on an audiogram. The pure tone average was calculated for each ear at speech frequencies (500, 1000, 2000 and 4000 hertz) [17] [18]. All those with $25 \mathrm{dBHL}$ or less were considered to have normal hearing thresholds while those with more than $25 \mathrm{dBHL}$ were considered to have abnormal hearing thresholds [18]. Hearing loss was classified as sensorineural (SNHL) if the air bone gap was less than $10 \mathrm{~dB}$ and conductive if the air bone gap was greater than 10dB. Mixed hearing loss is when the air bone gap was greater than $10 \mathrm{~dB}$ and bone conduction was impaired [17].

The hearing threshold was classified based on WHO (2014) as follows; no impairment $(0-25 \mathrm{~dB})$, mild hearing loss $(26-40 \mathrm{~dB})$, moderate hearing loss $(41-60 \mathrm{~dB})$, severe hearing loss $(61-80 \mathrm{~dB})$ and profound hearing loss $(>81 \mathrm{~dB})$

[17]. The hearing-threshold of the pupils was then compared based on their social class (low social class and high social class). Tympanometry was done to diagnosed otitis media with effusion (OME) using a Maico-Diagnostic EasyTymp Tympanometer (Model D-10587B, Germany), calibrated to ISO standard.

The data was analysed using the Statistical Product and Service Solutions (SPSS) software IBM SPSS Statistics for Windows, version 20 (IBM Corp., Armonk, N.Y., USA). Student t-test and Chi-square tests were used to test for possible difference or association. The level of statistical significance was set at p-value of $<0.05$.

\section{Results}

One hundred and three children were studied, 53 (51.5\%) were boys and 50 (48.5\%) were girls. The age ranged between 6 and 8 years with mean age of $6.8 \pm$ 
0.9. Fifty two (50.5\%) were from public school (low socio-economic class) and 51 (49.5\%) from private (high social class). Table 1 below gives the age and gender distribution of the participants.

The mean number of children per household from the low and high socioeconomic groups were $8.17 \pm 2.62$ and $3.51 \pm 2.59$ respectively. The difference in number of children per household between the two groups was statistically significant $(\mathrm{p}<0.001)$. However, the analysis revealed no statistically significant difference in terms of number of rooms per household between the two groups $(\mathrm{p}=0.206)$ (with mean of $2.98 \pm 1.35$ and $3.43 \pm 2.16$ between the lower and higher social class respectively).

Impacted wax was the most common ear condition encountered accounting for 37 (35.9\%) of all the children. Of those with ear wax, 22 (59.5\%) were from the low social class and 15 (40.5\%) were from high social class and the difference was not statistically significant ( $\mathrm{p}=0.173$ ). Of those with ear wax in the low social class; seven (31.8\%) had the wax on the right, four (18.2\%) on the left and 11 (50.0\%) were bilateral while ear wax was found in six $(40.0 \%)$ on the right, four (26.7\%) on the left and five (33.3\%) bilateral in children of high social class.

Table 2 showed that there was no statistically significant association between hearing loss and those who had ear wax (after ear wax removal) $\left(\chi^{2}=1.067, \mathrm{p}=\right.$ $0.302)$.

Foreign body was seen in three $(2.9 \%)$ children, two were from the low socio-economic group and one from the high socio-economic group. Seven (6.8\%) children had otitis media with effusion (OME) and of this, three (42.9\%) were from the lower socioeconomic class while four $(57.1 \%)$ were from the higher socioeconomic class. One pupil among those in the higher socioeconomic class had aural polyp in the right ear. None of the children in either the low or high social class had suppurative otitis media. Table 3 gives summary of otologic findings in the two groups.

Majority of the children in both the low and high socio-economic group had normal tympanogram (type A); three (5.8\%) of the children from the low socio-economic group and four (7.8\%) in the high socio-economic class had type B tympanogram.

Thirteen children (12.6\%) were hearing impaired: six (46.2\%) and seven (53.8\%) were from the low and high socioeconomic groups respectively. Of the six with hearing loss from the public school, three (50.0\%) were bilateral. Of the seven with hearing loss from the private school, four (57.1\%) were bilateral. Table 4 showed that the hearing loss was mostly conductive in nature and of mild degree in both the two groups.

\section{Discussion}

Diseases of the ear in children are a major public health issue particularly in developing countries [1] [4]. It has been suggested that all children in the developing countries should be screened at school entry for hearing impairment, discharge, OME and other ear diseases [1] [4]. 
Table 1. Age and gender distribution of participants.

\begin{tabular}{ccccccc}
\hline \multicolumn{6}{c}{ Low Social Class } & \multicolumn{2}{c}{ High Social Class } \\
\hline Age & Frequency & Percent & Frequency & Percent & $\chi^{2}$ & P-value \\
\hline 6 years & 29 & 55.8 & 19 & 37.3 & & \\
7 years & 8 & 15.4 & 15 & 29.4 & 4.329 & 0.115 \\
8 years & 15 & 28.8 & 17 & 33.3 & & \\
Total & 52 & 100 & 51 & 100 & & \\
Gender & & & & & & \\
Male & 23 & 44.2 & 30 & 58.8 & & \\
Female & 29 & 55.8 & 21 & 41.2 & 2.195 & 0.138 \\
Total & 52 & 100 & 51 & 100 & & \\
\hline
\end{tabular}

$x^{2}=$ Chi-Square

Table 2. Ear wax versus hearing threshold.

\begin{tabular}{ccccccc}
\hline & \multicolumn{7}{c}{ Ear Wax } & & \\
\cline { 2 - 6 } HT & Frequency & Percent & Frequency & Percent & $\chi^{2}$ & p-value \\
\hline NHT $(\leq 25 \mathrm{~dB})$ & 34 & 91.9 & 56 & 84.8 & & \\
AHT $(>25 \mathrm{~dB})$ & 3 & 8.1 & 10 & 15.2 & 1.067 & 0.302 \\
Total & 37 & 100 & 66 & 100 & & \\
\hline
\end{tabular}

$\mathrm{HT}=$ hearing threshold, $\mathrm{NHT}=$ normal hearing threshold, $\mathrm{AHT}=$ abnormal hearing threshold, $\mathrm{dB}=$ decibel; NB: Note that those who had ear wax had PTA done 3 days after syringing/removal.

Table 3. Summary of otologic findings among participants.

\begin{tabular}{|c|c|c|c|c|c|c|c|}
\hline & \multicolumn{2}{|c|}{ Low Social Class } & \multicolumn{2}{|c|}{ High Social Class } & \multirow[b]{2}{*}{ Total (\%) } & \multirow[b]{2}{*}{$x^{2}$} & \multirow[b]{2}{*}{ P-value } \\
\hline & Frequency & Percent & Frequency & Percent & & & \\
\hline \multicolumn{8}{|l|}{ Ear Wax } \\
\hline Present & 22 & 21.3 & 15 & 14.6 & 37 (35.9\%) & & \\
\hline Absent & 30 & 29.1 & 36 & 35.0 & $66(61.1 \%)$ & 1.860 & 0.173 \\
\hline Total & 52 & 50.5 & 51 & 49.5 & $103(100 \%)$ & & \\
\hline \multicolumn{8}{|l|}{ FB } \\
\hline Present & 2 & 1.9 & 1 & 1.0 & $3(2.9 \%)$ & & \\
\hline Absent & 50 & 48.5 & 50 & 48.5 & $100(97.1 \%)$ & 0.324 & 0.569 \\
\hline Total & 52 & 50.5 & 51 & 49.5 & $103(100 \%)$ & & \\
\hline \multicolumn{8}{|l|}{ OME } \\
\hline Present & 3 & 2.9 & 4 & 3.9 & $7(6.8 \%)$ & & \\
\hline Absent & 49 & 47.6 & 47 & 45.6 & $96(93.2 \%)$ & 0.175 & 0.676 \\
\hline Total & 52 & 50.5 & 51 & 49.5 & $103(100 \%)$ & & \\
\hline \multicolumn{8}{|l|}{$\mathrm{HL}$} \\
\hline Present & 6 & 5.8 & 7 & 6.8 & $13(12.6 \%)$ & & \\
\hline Absent & 46 & 44.7 & 44 & 42.7 & $90(87.4 \%)$ & 0.112 & 0.738 \\
\hline Total & 52 & 50.5 & 51 & 49.5 & $103(100 \%)$ & & \\
\hline
\end{tabular}

$\mathrm{FB}=$ foreign body, $\mathrm{OME}=$ otitis media with effusion, $\mathrm{HL}=$ hearing loss, $\chi^{2}=$ Chi-Square, $\%=$ percent. 
Table 4. Type and degree of hearing loss among pupils in low and high social class.

\begin{tabular}{ccccc}
\hline & \multicolumn{2}{c}{ Low Social Class } & \multicolumn{2}{c}{ High Social Class } \\
\hline Type of HL & Frequency & Percent & Frequency & Percent \\
\hline CHL & 7 & 13.5 & 9 & 17.7 \\
SNHL & 0 & 0.0 & 1 & 2.0 \\
Mixed & 2 & 3.8 & 1 & 2.0 \\
None & 43 & 82.7 & 40 & 78.4 \\
Total & 52 & 100 & 51 & 100 \\
Degree of HL & & & & 17.7 \\
Mild & 8 & 15.4 & 9 & 3.9 \\
Moderate & 1 & 1.9 & 2 & 78.4 \\
None & 43 & 82.7 & 40 & 100 \\
Total & 52 & 100 & 51 & \\
\hline
\end{tabular}

$\mathrm{HL}=$ hearing loss, $\mathrm{CHL}=$ conductive hearing loss, $\mathrm{SNHL}$ = sensorineural hearing loss; NB: Note that none of those in either social class had either moderately-severe, severe or profound hearing loss.

Wax impaction was the most common ear condition found in this study accounting for $35.9 \%$ of all the children. It was asymptomatic in most of the cases. Chishty et al. [15] similarly reported ear wax as being the commonest finding accounting for $41.9 \%$ in their study population. Although many studies reported lower prevalence of ear wax compared to this present study, it was still the most common otologic disease in majority of the studies [1] [6] [7] [19] [20] [21]. Thakur et al. [1] in Nepal, Kirfi et al. [6] in Nigeria, Chandha et al. [7] in India, Simoes et al. [19] in Kenya, Yamamah et al. [20] in Egypt and Mahmoud et al. [21] also in Egypt reported a prevalence of ear wax of $25.1 \%, 29.5 \%, 4.2 \%, 4.6 \%$, $7.9 \%, 9.5 \%$ and $21.3 \%$ respectively. Habitual use of cotton bud to "clean" the ears is a common practice in this part of the country [6], and may well account for this level of wax impaction. Wax impaction is mostly a silent condition but possibly has an influence on hearing capacity [1]. Some studies revealed that about $30 \%$ to $50 \%$ of wax impaction caused hearing impairment [22] [23]. However, in this present study, there was no statistically significant association between those who had ear wax and hearing loss $(\mathrm{p}=0.302)$. However, it is unknown whether cerumen lead to hearing loss as the hearing test was performed three days after cleaning the ears.

Of those with ear wax in this study, 59.5\% were from the low socioeconomic class and $40.5 \%$ were from high socioeconomic class and the difference was not statistically significant $(\mathrm{p}=0.173)$. However, Eziyi et al. [8] reported that wax impaction to be more common among the lower socioeconomic class (22.7\%) compared to those in high socioeconomic class (13.0\%).

All those with impacted wax in this current study had it removed by the researchers, using either Cawthorne wax hook and/or Jobson-Horne probe (29 children, $78.4 \%$ ) or ear syringing (eight children, $21.6 \%$ ). None had a complica- 
tion.

Otitis media with-effusion is chronic accumulation with non-purulent fluid within the middle ear cleft and the time that the fluid has to be present for the condition to be chronic is usually three months [24] [25]. The incidence of OME in children is mainly determined by the age of the child and the season of the year (generally highest in winter months) [24] [26] [27]. This may be explained by the increased number of upper respiratory tract (URT) infection during winter period. This study conducted in March 2017, showed a point incidence of $6.8 \%$ for OME, but no other types of otitis media were encountered. Al-Humaid et al. [9] in Saudi and Chishty et al. [15] in Bemina reported a similar finding of 7.5\% and 6.5\% respectively. Thakur et al. [1] in Nepal, Adhikari et al. [2] also in Nepal, Sallavaci et al. [4] in Albania, Chandha et al. [7] in India and Siddartha et al. [10] also in India, all reported a lower prevalence of OME of $1.1 \%, 3.7 \%$, $1.4 \%, 3.1 \%$ and $4.5 \%$ respectively. However, Yamamah et al. [20] and Sharath et al. [28] reported a higher prevalence of $10.8 \%$ and $13.3 \%$ respectively. Similarly, Nwosu and colleagues [25], in Nigeria reported a much higher prevalence of OME of $25.2 \%$. They attributed the high prevalence to high environmental pollution, humidity and high rainfall. Another reason for the high prevalence could be due to the difference in the methodology used, they studied $2-6$ years old children (this age group has the highest incidence of OME).

OME was evenly distributed between the two groups, 3 out of 52 and 4 out of 51 from the public and private schools respectively. Siddartha et al. [10] reported higher prevalence of OME of $70.0 \%$ among those in the lower socioeconomic class compared to $30.0 \%$ in children from the higher socioeconomic class. They concluded that children of low socioeconomic status were more susceptible to otitis media with effusion due to poor hygiene, overcrowding and poor nutritional status compared to those in the higher social class. Chandha et al. [7] in India, Al-Humaid et al. [9] in Saudi and Yadav et al. [11] also in India all reported higher prevalence of OME among those from the lower socioeconomic status. This present study did not show any such difference between the two groups.

Similarly, studies have shown that overcrowding was associated with increased incidence of otitis media [11] [29] [30], but this could not be established from this present study which revealed no difference in occurrence of OME between the lower and higher socioeconomic groups despite the significant difference noted between the two groups in terms of number of children per household.

Thirteen children (12.6\%) had hearing loss on audiometric assessment, most of it conductive in nature, and of mild degree (Table 4). This is comparable to findings by Chishty et al. [7] in Bemina, Yamamah et al. [20] in Egypt and Absalan et al. [31] in Iran. Sallavaci and colleagues [4], in Albania reported a lower prevalence of hearing loss of $4.4 \%$. However, Skarzynski et al. [32] in Poland, Obukowho et al. [33] in Nigeria, Klas et al. [34] in Brazil and Nogueira et al. [35] all reported higher prevalence of hearing loss of $23.7 \%, 29.4 \%, 29.5 \%$ and $34.0 \%$ 
respectively.

The hearing loss was almost equally distributed between the two groups (46.2\% in lower socioeconomic group and $53.8 \%$ in the higher socioeconomic group). However, Vasconcellos et al. [12] and Obukowho et al. [33] in their different studies all reported that hearing loss was more prevalent among children of low socioeconomic status.

\section{Conclusion}

Wax impaction was the commonest otologic condition found in this study population, irrespective of social class. Our study showed a point incidence of $6.8 \%$ for OME, but there was no statistical difference between the two socio-economic groups, and neither was there any statistically significant difference in any of the other diseases encountered. This study did not demonstrate any direct impact of socioeconomic status in the pattern of ear diseases in children.

\section{Limitations}

Hearing test was not carried out in a sound proof booth; background noise may have affected the hearing thresholds.

\section{Presentation at a Meeting}

Presented as "Poster Presentation" in July 2018 at BACO International Conference, $\mathrm{UK}$.

\section{Conflicts of Interest}

The authors declare no conflicts of interest regarding the publication of this paper.

\section{References}

[1] Thakur, S.K., Singh, S.K., Mahato, B., Singh, A. and Mahato D. (2015) Pattern of Otological Diseases in School-Going Children of the Sunsari District of Eastern Nepal. Internet Journal of Otorhinolaryngology, 17, 1-5.

[2] Adhikari, P., Kharel, B., Ma, J., Baral, R., Pandey, T., Rijal, R., et al. (2008) Pattern of Otological Diseases in School Going Children of Kathmandu Valley. International Archives of Otorhinolaryngology, 12, 502-505.

[3] Kirfi, A., Mainasara, G., Sa'idu, A.T., Fufore, M. and Joseph, Y. (2014) Cerumen Auris in Abubakar Tafawa Balewa University Teaching Hospital Bauchi, North-Eastern Nigeria. Sudan Medical Monitor, 9, 75-80. https://doi.org/10.4103/1858-5000.146579

[4] Sallavaci, S., Toci, E., Sallavaci, Y. and Stroni, G. (2014) Prevalence of Hearing Loss among First Grade School Children in Tirana, Albania-A Repeated Cross-Sectional Survey. Otolaryngology, 4, Article No. 174. https://doi.org/10.4172/2161-119X.1000174

[5] Johnson, D., Swank, P.R., Owen, M.J., Baldwin, C.D., Howie, V.M. and McCormick, D.P. (2000) Effects of Early Middle Ear Effusion on Child Intelligence at Three, Five, and Seven Years of Age. Journal of Pediatric Psychology, 25, 5-13.

[6] Kirfi, A.M., Fufore, M.B., Samdi, M.T. and Salisu, A.D. (2019) Wax Impaction 
among School Children Aged 7-17 Years in Kaduna Metropolis, Kaduna, Nigeria. Otolaryngology (Sunnyvale), 9, 376-377. https://doi.org/10.1093/jpepsy/25.1.5

[7] Chadha, S.K., Agarwal, A.K., Gulati, A. and Garg, A. (2006) A Comparative Evaluation of Ear Diseases in Children of Higher versus Lower Socioeconomic Status. The Journal of Laryngology \& Otology, 120, 16-19. https://doi.org/10.1017/S0022215105001520

[8] Eziyi, J.A., Amusa, Y.B., Nwawolo, C.C. and Ezeanolue, B.C. (2011) Wax Impaction in Nigerian School Children. East Central African Journal of Surgery, 16, 40-45.

[9] Al-Humaid, H. and Abou-Halawa, A. (2014) Prevalence and Risk Factors of Otitis Media with Effusion in School Children in Qassim Region of Saudi Arabia. International Journal of Health Sciences, 8, 329-338. https://doi.org/10.12816/0023990

[10] Siddartha, Bhat, V., Bhandary, S., Shenoy. V. and Rashmi (2011) Otitis Media with Effusion in Relation to Socio Economic Status: A Community Based Study. Indian Journal of Otolaryngology and Head \& Neck Surgery, 64, 56-58. https://doi.org/10.1007/s12070-011-0163-4

[11] Yadav, S., Saxena, S., Sharma, H., Singh, I. and Singh, J. (2006) Secretory Otitis Media: A School Health Survey. Indian Journal of Otolaryngology and Head and Neck Surgery, 58, 250-252.

[12] Vasconcellos, A.P., Colello, S., Kyle, M. and Shin, J. (2014) Societal-Level Risk Factors Associated with Pediatric Hearing Loss. Otolaryngology-Head and Neck Surgery, 151, 29-41. https://doi.org/10.1177/0194599814526561

[13] Rose, D. and Pevalin, D.J. (2001) The National Statistics Socioeconomic Classification: Unifying Official and Sociological Approaches to the Conceptualisation and Measurement of Social Class. ISER Working Paper Series, University of Essex, Institute for Social and Economic Research (ISER), Colchester.

[14] Olawale, S. (2017) Federal Civil Service Commission Salary Structure-Details and Analysis. https://naijaquest.com/federal-civil-service-commission-salary-structure/

[15] Chishty, L.S., Hamid, S., Mohd, E., Chishty, L. and Wani, A. (2014) A Prospective Study of Hearing Impairment in School Going Children of Ghaziabad City Attending a Tertiary Care Hospital. Otolaryngology Online Journal, 4, 1-13.

[16] Wong, T.W., Yu, T.S., Chen, W.Q., Chiu, Y.L., Wong, C.N. and Wong, A.H.S. (2003) Agreement between Hearing Thresholds Measured in Non-Sound Proof Work Environment and a Sound Proof Booth. Occupational and Environmental Medicine, 60, 667-671. https://doi.org/10.1136/oem.60.9.667

[17] Kirfi, A.M., Samdi, M.T., Salisu, A.D. and Fufore, M.B. (2019) Hearing Threshold of Deaf Pupils in Kaduna Metropolis, Kaduna Nigeria: A Cross-Sectional Survey. Nigerian Postgraduate Medical Journal, 26, 164-168. https://doi.org/10.4103/npmj.npmj 5619

[18] Fufore, M.B., Kirfi, A.M., Salisu, A.D., Samdi, T.M., Abubakar, A.B. and Onakoya, P.A. (2019) Prevalence and Pattern of Hearing Loss in Patients with Chronic Kidney Disease in Kaduna, Northwestern Nigeria. Indian Journal of Otology, 25, 201-205. https://doi.org/10.4103/indianjotol.INDIANJOTOL $94 \quad 19$

[19] Simoes, E., Kiio, F., Carosone-Link, P., Ndegwa, S., Ayugi, J. and Macharia I. (2016) Otitis Media and Its Sequelae in Kenyan Schoolchildren. Journal of the Pediatric Infectious Diseases Society, 5, 375-384. https://doi.org/10.1093/jpids/piv038

[20] Yamamah, G., Mabrouk, A., Ghorab, E., Ahmady, M. and Abdulsalam, H. (2012) Middle Ear and Hearing Disorders of Schoolchildren Aged 7-10 Years in South Sinai, Egypt. Eastern Mediterranean Health Journal, 18, 255-260. https://doi.org/10.26719/2012.18.3.255 
[21] Mahmoud, R., Shabana, M., Seleit, A., El-hamshary, A. and Hosnid, N. (2016) School-Based Hearing Screening Program in Children, Four to Seven Years Old, Quesnay City, Minufia, Egypt. Advanced Arab Academy of Audiovestibulogy Journal, 3, 35-42. https://doi.org/10.4103/2314-8667.202553

[22] Sharma, H., Bhusan, V., Dayal, D. and Mishra, S.C. (1992) Preliminary Study of Hearing Handicap in School-Going Children. Indian Journal of Otolaryngology and Head and Neck Surgery, 30, 119-124.

[23] Jacob, A., Rupa, V., Job, A. and Joseph, A. (1997) Hearing Impairment and Otitis Media in a Rural Primary School in South India. International Journal of Pediatric Otorhinolaryngology, 39, 133-138. https://doi.org/10.1016/S0165-5876(96)01479-6

[24] Al-Juboori, A.N., Al-Aqeedee, A.A. and Saeed, H.D. (2014) Otitis Media with Effusion in Children: A Follow up Study in West Baghdad, Iraq. Journal of Communication Disorders, Deaf Studies \& Hearing Aids, 2, 1-5.

[25] Nwosu, C., da Lilly-Tariah, O.B. and Onotai, L.O. (2017) Prevalence of Otitis Media with Effusion among Preschool Children in Port Harcourt, Nigeria. Global Journal of Otolaryngology, 4, 1-5. https://doi.org/10.9734/IJTDH/2017/31363

[26] Di Francesco, R.C., Barros, V.B. and Ramos, R. (2016) Otitis Media with Effusion in Children Younger than 1 Year. Revista Paulista de Pediatria, 34, 148-153. https://doi.org/10.1016/j.rppede.2016.01.003

[27] MacIntyre, E.A., Karr, C.J., Koehoorn, M., Demers, P., Tamburic, L., Lencar, C. and Brauer, M. (2010) Otitis Media Incidence and Risk Factors in a Population-Based birth Cohort. Paediatrics \& Child Health, 15, 437-442.

https://doi.org/10.1093/pch/15.7.437

[28] Sharath, B., Prabakaran, J. and Radhakrishnan, S. (2016) Prevalence and Management of Otitis Media with Effusion amongst the School Going Children of a Rural Area in Puducherry. Bengal Journal of Otolaryngology and Head Neck Surgery, 24, 22-28. https://doi.org/10.47210/bjohns.2016.v24i1.68

[29] Amusa, Y.B., Ijaduola, I.K. and Onayade, O.O. (2005) Epidemiology of Otitis Media in a Local Tropical African Population. West African Journal of Medicine, 24, 227-230. https://doi.org/10.4314/wajm.v24i3.28202

[30] Bowie, C., Pearson, A.L., Campbell, M. and Barnett, R. (2014) Household Crowding Associated with Childhood Otitis Media Hospitalizations in New Zealand. Australian and New Zealand Journal of Public Health, 38, 211-215. https://doi.org/10.1111/1753-6405.12162

[31] Absalan, A., Pirasteh, I., Dashti-Khavidaki, G.A., Asemi-Rad, A., Esfahani, AN. and Nilforoush, M.H. (2013) A Prevalence Study of Hearing Loss among Primary School Children in the South East of Iran. International Journal of Otolaryngology, 2013, Article ID: 138935. https://doi.org/10.1155/2013/138935

[32] Skarzynski, P., Swierniak, W., Piłka, A., Skarżynska, M., Włodarczyk, A., Kholmatov, D., et al. (2016) A Hearing Screening Program for Children in Primary Schools in Tajikistan: A Telemedicine Model. Medical Science Monitor, 22, 2424-2430. https://doi.org/10.12659/MSM.895967

[33] Obukowho, O.L., Enekole, O.J. and Ifeoma, A. (2017) Risk Factors of Hearing Impairment among Lower Primary School Children in Port Harcourt. Global Journal of Otolaryngology, 5, Article ID: 555675. https://doi.org/10.19080/GJO.2017.05.555675

[34] Klas, R. and Lacerda, A. (2014) The Audiometric Findings among Curitiba and Metropolitan Area Students. International Archives of Otorhinolaryngology, 18, 165-171. https://doi.org/10.1055/s-0034-1366975 
[35] Nogueira, J.C.R. and Mendonca, M.D.C. (2011) Assessment of Hearing in a Municipal Public School Student Population. Brazilian Journal of Otorhinolaryngology, 77, 716-720. https://doi.org/10.1590/S1808-86942011000600007 